\title{
Colony-Forming Unit-Granulocyte Macrophage Assay
}

National Cancer Institute

\section{Source}

National Cancer Institute. Colony-Forming Unit-Granulocyte Macrophage Assay. NCI Thesaurus. Code C63799.

A functional (qualitative) as well as quantitative assay that is utilized as an indicator of granulopoiesis reconstitution. 